\title{
A conceptual framework to explain the impact of visitors' previous experiences on customer satisfaction
}

Suleyman Numan $\mathrm{Oz}$

Limkokwing University of Creative Technology

Ali Ihtiyar

Universiti Teknologi Malaysia

Fauziah Sh Ahmad

Universiti Teknologi Malaysia

Faizan Ali

Florida State University

\section{Recommended Citation}

Oz, S. N., Ihtiyar, A., Ahmad, F. S., \& Ali, F. (2016). A conceptual framework to explain the impact of visitors' previous experiences on customer satisfaction. International Interdisciplinary Business-Economics Advancement Journal, 1(1), 38-49. 


\title{
A Conceptual Framework to Explain the Impact of Visitors' Previous Experiences on Customer Satisfaction
}

\author{
Suleyman Numan $\mathrm{Oz}^{1}$, Ali Ihtiyar ${ }^{2}$, Fauziah Sh $\mathrm{Ahmad}^{3}$ and \\ Faizan $\mathrm{Ali}^{4}$ \\ Limkokwing University of Creative Technology \\ 1nmnoz45@gmail.com \\ International Business School \\ Universiti Teknologi Malaysia \\ 2aliihtiyar@gmail.com \\ ${ }^{3}$ fsa@ibs.utm.my \\ Dedman School of Hospitality The College of Business \\ Florida State University \\ ${ }^{4}$ faizanali7@ hotmail.co.uk
}

\begin{abstract}
The article presents a comprehensive and conceptual framework on key factors of intercultural interaction influencing customer satisfaction, which is one of the most important indicators of tourism industry in Malaysia. The theory-based path model of constructs and their possible interrelationships will be proposed such that the future analysis would be based on structural equation modeling approach or related statistical methods. In other words, this study anticipates to propose an applicable technique to empirically examine the inter relationships of intercultural communication competence, interaction comfort, inter-role congruence, perceived cultural distance, previous experience and satisfaction. It is basically a literature reviews on the related constructs and how the relationships' assessment of those constructs should be carried out. Although numerous researchers have studied the extensive topics of cultural distance and customer satisfaction, none of those studies has explored on the critical role of intercultural communication competence and previous experience on customer satisfaction in the industry.
\end{abstract}

Keywords: previous experience, intercultural communication competence, perceived cultural distance, tourism, Malaysia

\section{Introduction}

The cross-cultural understanding themes and concepts have gained quite an attention among social science researchers in explaining consuming features, perceptions on educational activities and adaptation processes of individual who are participating from different cultures to host culture (Baker, Cronin, \& Hopkins, 2009; Ihtiyar \& Ahmad, 2015a; Ihtiyar \& Ahmad, 2015b; Polsa, Fuxiang, Sääksjärvi, \& Shuyuan, 2013). Furthermore, in marketing literature there are some studies such as employee performance in hospitality industry in cross-cultural service encounters (Sizoo, Iskat, Plank, \& Serrie, 2004); similarities and differences in complaining 
attitudes and behaviors of hotel customer base on different nationality (Yuksel, Kilinc, \& Yuksel, 2006). Most discussions on cross-cultural communications reflect the significance of crosscultural communication for organizations and institutions intend to penetrate their internationalization activities particularly when the culture of the new society differs from the base or origin society. In regarding this perspective, this study is focusing on Malaysia, a country with multicultural uniqueness and with greater needs for intercultural understanding and communication in tourism and hospitality industry. The attractive multicultural Malaysia poses greater challenges for individuals to sharpen their cross-cultural communication compared to the other more culturally uniform Asian societies such as China, Japan and Korea. Malaysia presents an extremely multicultural and combined ethnic structure of three dominant groups with the percentage of Malays at 50.35\%, Chinese at 22.21\% and Indians at $6.67 \%$ and other races for the remaining percentage (Statistics Department of Malaysia, 2013). According to statistics of Tourism Malaysia (2015), tourist arrivals increased year by year last years such as 27.437 million in 2014; 25.72 million in 2013; 25.03 million in 2012; 24.71 million in $2011 ; 24.58$ million in 2010; 23.65 million in 2009. The percentage for expansion from 2009 to 2014 was $14 \%$ and expected arrival for 2020 is 36 million.

Due to the cultural variations, there is an obvious deficiency of behavior homogeneity where the nature of Malaysia domestic society is highly categorized by the ethnically segmented society (Mokhlis, 2009). The background of cultural segments must be combined into a universal theory specifically in social sciences, cross-cultural interaction and communication as this would better explain the highly visible differences in cross-cultural communication (Cleveland, Laroche, \& Papadopoulos, 2009; Shekarchizadeh, Rasli, \& Hon-Tat, 2011). However only a few of earlier studies have explained how the proper intercultural communication competence (ICC) between culturally diverse service encounters (CDSEs) has a significant influence or consequences on cross-cultural communication (Danylova, 2013; Herzog, 2010; Ihtiyar \& Ahmad, 2015b). It is also noted that in those earlier discussions, there is even a wider a gap of knowledge in explaining the antecedents of intercultural communication competence. Therefore, the study intends to explain the role of previous experience on perceived cultural distance that drives to customer satisfaction through inter-role congruence, interaction comfort and ICC. The proposition is based on a theory referred to as "role theory" which posits that people interact in socially defined role (Biddle, 1979) and hence determine expectations. However, visitors may also be expected to interact in multiple roles that could lead to contradictory expectation or causing conflicts. The other theory contributing to this proposal is described as "Interdependence theory" which identifies that most important characteristic of interpersonal situations is not just from intrapersonal perspectives but also through interpersonal process or a comprehensive analysis of situation structure (Rusbult \& Van Lange, 2008). The theory hypothesizes that the ability of a person to interact in social environment is partly due to the anticipation of the social reward or enjoyable social comforts.

Consequently, the structure of the paper is as follows. Firstly, it discusses the literature review, which focuses on the theoretical background for the research, which leads to the research hypotheses. Then, it proposes the suitable research framework and the research design. Finally, it concludes with a discussion on expectation of findings and key suggestions for future research. 


\section{Literature Review}

This literature review will focus on the theoretical background of the research, which is focusing on two major theories namely Role Theory and Interdependence Theory. It will also explain the research constructs of the proposed research framework by understanding its embedded theory and past literature. Then it will suggest the research hypotheses that explain the interrelationships between the constructs.

\section{Theoretical Background}

\section{Role Theory}

Role theory was primarily encouraged by Biddle (1979) and later by Solomon, Surprenant, Czepiel, \& Gutman (1985) to posit that individuals interact in socially outlined role and hence determine expectations. It is considered as "a science concerned with the study of behaviors that are characteristic of persons within contexts and with processes that produce, explain or are affected by these behaviors" (Biddle, 1979). In accordance with this definition, the concentration of the theory among researchers is mainly on recognition of interaction of CDSEs on anticipated encounters' behaviors.

One of the significant topics, which is relating to the Role theory is recognition on the importance of the person-to-person interaction in terms of intercultural context and its overall influence on basic outcomes of cross-cultural communication such as communication satisfaction and continuity (Sharma, Tam, \& Kim, 2012). In terms of this perspective, "personto-person" interaction is becoming critical indicator to decrease the level of communication conflict for intercultural encounters (Ihtiyar, Ahmad, \& Baroto, 2013; Paswan \& Ganesh, 2005). To an extent, culturally diverse encounters that are involved in cross-cultural communication are considered as the part of cross-cultural social environment (Solomon et al., 1985). Although the role of culturally diverse service encounters (CDSEs) in interaction is significant; however, the interaction is not explained as straight. Instead, it is a shared and interactive experience among the CDSEs.

\section{Interdependence Theory}

The perspective of Interdependence theory is founded on systematic analysis of structure of interpersonal interaction (Paswan \& Ganesh, 2005; Sharma et al., 2012). The theory is suggesting an analytical and reasonable process to better understand specific situations, motivations, problems, and opportunities via the concept of transformation. The theory illuminates our thought of social-cognitive processes, attributions, and self-presentations for CDSEs and it enlightens adaptation, characterization, relationships and social norms of CDSEs through unplanned and intended situations (Rusbult \& Van Lange 2003).

The theory also categorizes the most important characteristics of interpersonal situations are not just from intrapersonal perspectives but also through interpersonal process or a comprehensive analysis of situation structure (Rusbult \& Van Lange, 2008). Few studies on the theory resulted in few interesting findings. For instance, an individual in multicultural social environment who has a foreign accent is frequently more culturally distant than another individual who can speak official language fluently (Hill \& Tombs, 2011). Another finding indicates linguistic ability of employee in an organization (i.e. American, British and Indian accent) is influencing another 
CDSEs' perceptions and interpretations during the service experiences in the call centre setting (Wang, Arndt, Singh, \& Biernat, 2009). Thus, clarifying, describing and decoding the interaction among the encounters is a crucial process to better understand the consequences and possible outcomes of encounters.

\section{The Research Constructs}

\section{Intercultural Communication Competence}

Since meaning of competence is a person's attitudes, knowledge and skills (Hunt \& Wallace, 1997), intercultural communication competence (ICC) is "the ability to think and act in appropriate ways with people from other cultures" (Friedman \& Antal, 2005). ICC is the capacity to communicate efficiently and appropriately with individuals of dissimilar cultures (Messner \& Schäfer, 2012). It deals with the ability to think positively, distinguish the differences, internalize various cultural settings, manage the experiences accurately and construct an effective communication in the most appropriate way with individuals from different cultures in the cross-cultural environment (Ahmad, Ihtiyar, \& Omar, 2015; Friedman \& Antal, 2005). Due to the enormous growth in the tourism and hospitality industry, global players are considering long-term business success and stabile expansion (Yim, Tse, \& Chan, 2008). Therefore, in contrary to physical needs in a service setting, employees in tourism and hospitality industry are becoming more critical indicator for the firms in the industry. Furthermore, welltrained service employees are playing significant role for long-terms business success in the industry. Therefore, in terms of tourism and hospitality literature, service employees' crosscultural skills not only effective on service attentiveness; it is also effective on selling skills (Sizoo et al., 2004). However, customers' perceptions in tourism and hospitality industry have been evaluated without impact of intercultural communication competence on inter-role congruence and interaction comfort in emerging economies such as in Malaysia.

Individuals with stronger ICC have greater propensity to learn foreign languages and norms or values of other cultures. They can communicate effectively with people from different cultural backgrounds (Lustig \& Koester, 2009; Thomas et al., 2008). Furthermore, revenue contribution, service concentration, interpersonal skills and job satisfaction are influenced by CDSEs' intercultural thoughtfulness (Sizoo, Plank, Iskat, \& Serrie, 2005). However, most of the CDSEs' expectations and reactions have been examined without ICC (Ryoo, 2005). The study on the other hand proposes an exploration on the antecedents of ICC (based on the interdependence theory) and its immediate consequence on positive cognitive reward such as interaction comfort and interrole congruence (based on both of the Interdependence theory and the Role theory). Although it is understood that the positive cognitive reward will lead to decrease the communication conflict level, the limit of this discussion is on the two most important antecedents (perceived cultural distance and previous experience) and immediate cognitive consequences (interaction comfort and inter role congruence) of ICC based on the discussed theories.

Individuals with lower ICC are likely to feel less comfortable and expose weak inter-role congruence in intercultural encounters compared to those with higher levels of ICC (Friedman \& Antal, 2005). Those with higher ICC exhibit more empathy and respect for individuals from other cultures, respond to curious circumstances and behaviors in a non-judgmental way without 
showing visible or perceivable discomfort, and enthusiastically use their knowledge and experience to predict various expectations in numerous situations (Lustig \& Koester, 2009). Individuals with higher intercultural communication competence also may not only be more aware of cross-cultural differences in service roles and perceptions, however they are also more likely to agree with these differences. Furthermore, they have greater experience and knowledge about other cultures and are able to use this experience and knowledge efficiently with people from other cultures, compared to those with lower ICC (Earley, Murnieks, \& Mosakowski, 2007; Thomas et al., 2008). Hence, higher ICC may also contribute in reducing discomfort and uncertainty generally associated with intercultural service encounters. The study thus proposes ICC predicts interaction comforts and inter-role congruence.

\section{Interaction Comfort}

Earlier studies in psychology and sociology have provided several validated reasons of increasing encounters comfort during interaction of CDSEs. Strengthened interaction comfort leads to decrease the perceived risk and increased confidence, trust, interaction satisfaction and improved relational exchange (Lloyd \& Luk, 2011; Paswan \& Ganesh, 2005; Sharma et al., 2012; Spake, Beatty, \& Brockman 2003).

Customers consider many different dimensions of services to see whether their expectations and perceptions match with each other to get satisfactory outcome (Raajpoot, 2004). Customers also take into consideration of sincerity, politeness, empathy and friendly approach of employees during service interaction. As emphasized in the study of Lloyd \& Luk (2011), service employee behavior against customer such as voice level during interaction, knowledge of foreign language and facial expression is crucial in terms of customers' interaction comfort.

As indicated in the Interdependence Theory (Surprenant, Solomon, \& Gutman, 1983), each part of interaction has an impact on another part because behavior of the second part is influenced by the outcomes of the first part. In other words, the CDSEs are not independent and it may increase the level of knowledge on each other parts and also reduce possible risks and uncertainty. Basically, interaction comfort is defined as the likeliness individuals share common norms, values, languages and other factors related to culture and this will improve predictability of visitors' expectations and behavior, decrease uncertainty and create a effective communication. On the other spectrum, perceived dissimilarities in behavioral values or norms such as on language, religion and so on will lead to a sense of discomfort (Ahmad, Ihtiyar, \& Omar, 2014; Ihtiyar, Ahmad, \& Baroto, 2013). In this study, interaction comfort is one of the critical dimensions for reflecting the impact of perceived cultural distance and ICC on customer satisfaction. In the study, the impact of interaction comfort on customer satisfaction and perceived cultural distance is explaining through ICC.

\section{Inter-Role Congruence}

A constructive interaction outcome depends on role clarity, and it should be understood each other's roles and perceptions during communication (Solomon et al., 1985). Unfortunately, even when CDSEs happen among between people of similar cultures, they may have different perceptions about each other, or they may not always be able to act within their expected roles in interaction (Baker et al., 2009). The inter-role congruence would be more complicated in intercultural interactions where CDSEs must consider the different ethic roles among CDSEs. 
According to the role theory (Solomon et al., 1985), the level of conflict and misunderstanding that are caused by the role perception (the degree of understanding and agreement between both sides on each other's role in an interaction) may involve breaking the communication between CDSEs, and it may lead to a dissatisfied communication experience for CDSEs. Moreover, as highlighted in the studies of Nicholls (2011); Reimann, Lünemann, \& Chase (2008); Hofstede (1984), individuals from high-power distance cultures, individualistic background, high uncertainty avoidance cultures represent distinctive differences on inter-role congruence in the context of CDSEs. Inter role congruence would consequently positively affect interaction of CDSEs.

\section{Perceived Cultural Distance}

Due to the dissimilarities or familiarities of CDSEs indicate important changes in their expectation and / or perceptions on cross-cultural experiences and, hence, cross-cultural satisfaction is influenced by their pre-conceptions (Sharma et al., 2012). In literature of sociology, social psychology and associated fields, dissimilarities or familiarities of individuals have been investigated under cultural distance. Instead of the general approach, the study will concern to apply Sharmas' et al. (2012) method, which is entitled "perceived cultural distance" for measure of overall differentiation among individuals from different cultures.

Knowledge about destinations' culture may play a crucial role for reducing perceived risk and uncertainty (Weaver, 1998). According to the study of Weaver (1998), "the more we know about the dynamics of cross-cultural communication, adjustment and conflict, the more effective we will be while living or working in another culture and the severity and duration of the stress of adjusting to that culture (culture shock) may be lessened using this knowledge". Therefore, as highlighted in the studies of McKercher, Wong, \& Lau (2006) and Sharma et al. (2012) CDSEs prefer to communicate with individuals whose culture is the same or similar to their culture.

Even though the model of Sharma et al. (2012) is considered as inspired study for the study, their research has been proposed a concept, which is behind perceived cultural distance. For instance, their model focused on only perceived cultural distance. The study adds 'previous experience' a new dimension to understand the impact of visitors past experience on perceived cultural distance.

\section{Previous Experience}

Although there are many definitions of customers' previous experiences in the literature (Kim \& Brown, 2012), however, a limited studies in a tourism and hospitality have been explained the concept of customers' previous experience (Zemke \& Pullman, 2008). Common perspective on customer experience in the literature is considering on employee and customer communication that affects customer spiritually, emotionally, intellectually and physically (Mossberg, 2007); "the total outcome to the customer from the combination of environment, goods and services purchased" (Lewis \& Chambers, 2000). In contrary to these studies, the present study is assumed the definition of customers' previous experience as "tourist goes through at a destination is an experience, be it behavioral or perceptual, cognitive or emotional, expressed or implied" (Oh, Fiore \& Jeoung, 2007). 
Many firms give priority to customer experiences to be strong against competitors in this competitive market (Cetin \& Dincer, 2014) which means that services, products and assets are not enough alone without customer experiences for long term profits (Cetin \& Dincer, 2014). As tourism is mainly based on experience-intensive industry, visitors consider prior experiences to visit a place (Ali, Hussain, \& Ragavan, 2014). Besides this fact, cultural distance also has an effect on experience as highlighted in the study of Cho and Padmanabhan (2005) "Higher levels of experience may counteract the negative effects of high levels of cultural distance" .

As stated under the title of "perceived cultural distance", the proposed study will employ Sharma et al. (2012) approach to conceptualized the perceived cultural distance. Although, their model has not connected to previous experiences of the visitors; however, the study will show whether previous experience has an impact on perceived cultural distance or not. Therefore, the proposed study is assumed that previous experience has impact on perceived cultural distance. Accordingly, the predictability of perceived cultural distance and its concept will be more inclusion and effective.

\section{Customer Satisfaction}

Customer satisfaction has aroused long-term interest in many fields (Li, Ye \& Law, 2013). Beyond that, Customer satisfaction in the tourism and hospitality industry has been one of the most examined topics for decades (Golder, Mitra \& Moorman, 2012). Since there are many definitions of customer satisfaction in the literature, the most applied one is Oliver, Rust, and, Varki's (1997) definition, which is "the consumer's fulfillment response. It is a judgment that a product or service feature, or the product or the service itself, provided (or is providing) a pleasurable level of consumption-related fulfillment, including levels of under or over fulfillment" (Oliver et al., 1997, p. 13). The present study will follow the definition of customer satisfaction as " customer's overall emotional response to the entire intangible service." which is more suitable for hospitality industry (Li et al., 2013).

Managers mainly plan long term profit rather than short term for their companies. In this respect, Chen, Liu, Sheu, and Yang (2012) have found out that customer satisfaction is crucial for firms' long-term profit. Therefore, satisfied customers stay longer and the customer who stays longer brings more profit to the company (Ihtiyar \& Ahmad, 2012; Sim, Mak \& Jones, 2006). Furthermore, satisfied customers show lesser complaints (Ahmad, Ihtiyar, Jing, \& Osman, 2012; Michel \& Meuter, 2008) and they may come back the company in the future (Hui, Wan, \& Ho, 2007; Kim, Kim, \& Miner, 2009; Su, Swanson, \& Chen, 2016).

There are several studies on customer satisfaction in selecting accommodations in the tourism and hospitality literature. In this sense, Ramanathan (2012) have studied the impact of product quality in the UK hotels, Yang, Jou, and Cheng (2011) have studied employees' service attitude in Taiwan hotels, Nam, Ekinci, and Whaytt (2011) have studied staff behaviour and physical quality in UK hotels, Han, Kim, and Kim (2011) have studied service encounter performance in US hotels, Sánchez-Hernández, Martínez-Tur, Peiró, and Ramos (2009) have studied functional and relational service quality, Zhang and Li, (2009) have studied employees' behaviour in budget hotels, Wu and Liang (2009) have studied interaction between customer to customer and interaction between service provider and customer in hotel restaurants. In the study, the impact of previous experience, perceived cultural distance, inter-role congruence, inter action comfort 
and intercultural communication competence on customer satisfaction in Malaysia will be proposed to further examinations.

\section{Interrelationship among Constructs}

The study proposes a framework to research the impact of previous experience and perceived cultural distance on interaction comfort and interrole congruence. The framework also includes the consequence of ICC on the inter-role congruence and interaction comfort among the individuals of multicultural Malaysia as shown in hypotheses below.

H1: Interaction comfort determines customer satisfaction.

$\mathrm{H} 2$ : Inter-role congruence determines customer satisfaction.

H3: Intercultural communication competence determines interaction comfort.

H4: Intercultural communication competence determines inter-role congruence.

H5: Perceived cultural distance determines interaction comfort.

H6: Perceived cultural distance determines inter-role congruence.

H7: Previous experience determines perceived cultural distance.

H8: Intercultural communication competence moderates between perceived cultural distance determines inter-role congruence.

H9: Intercultural communication competence moderates between perceived cultural distance determines interaction comfort.

\section{Research Framework and Design}

This paper intends to propose an appropriate research framework and research design to empirically examine the interactions among the various constructs discussed above. The proposed research framework is based on the proposed theories and shown in Figure 1. The following discussion explains and justifies the research design, as well as detailing its administrative procedures or operational framework to examine the data.

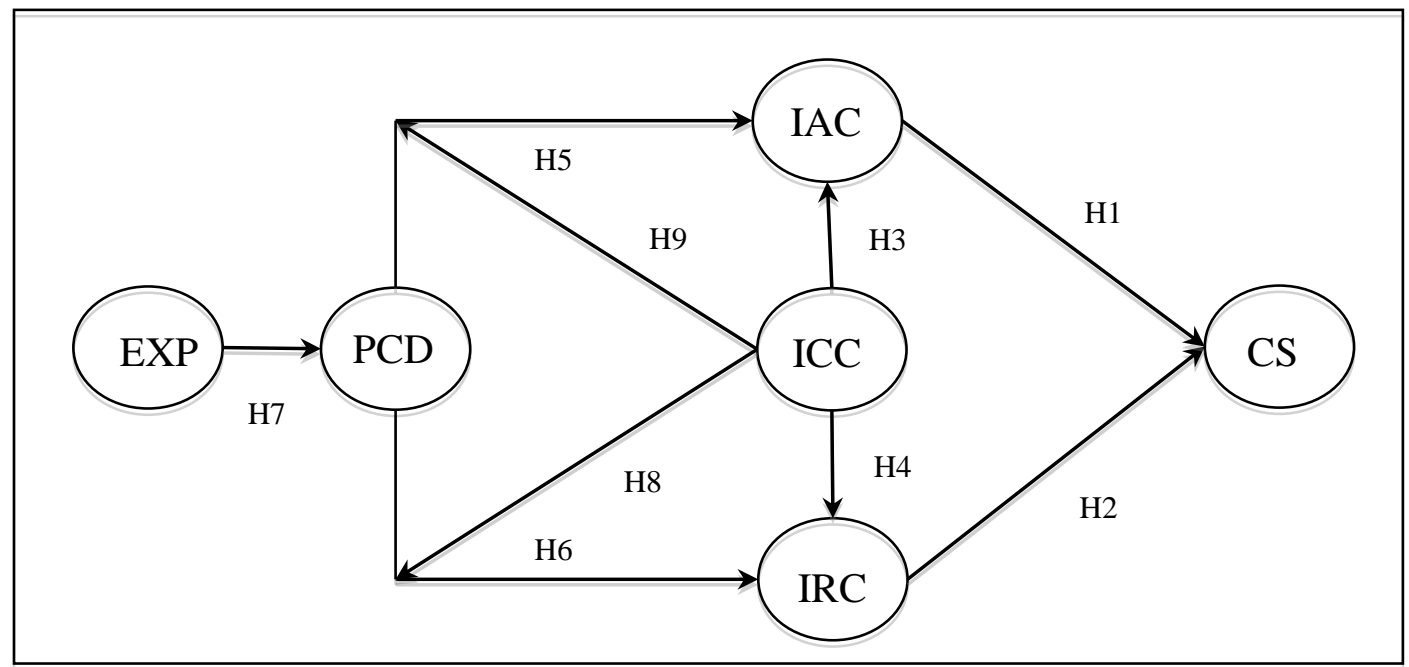

Source: Developed for this Research

Figure 1: Research framework 
In regarding to design the research, nature of the research problems and the objectives of the study, which then transformed into the conceptual framework, functioned as a basis to indicate the types of design to be applied. This research intends to test whether the propose model is a valid way to conceptualize and explain the endogenous and exogenous variables related to ICC in multicultural atmosphere. It may start with the further investigations on relevant constructs through substantial literature review and expert opinions in order to clarify and define the nature of notions. Continuance to that, based on the established conceptual framework, questionnaire survey will be developed. The survey design should incorporate available tools from existing theories and literature on each of the recognized elements of the research constructs as discussed earlier.

The next step would be conducting fieldwork study or collecting the survey data among the respondents to examine and measure the latent constructs based on the selected parameters and variables. In this major quantitative phase, the study may apply structural equation modeling (SEM) technique to assess the relationships between the constructs and consequently address the hypotheses and model fit. The advantage of the technique is that it combines the principle of factor analysis and multiple regressions in one procedure (Hair, Hult, Ringle, \& Sarstedt, 2013). Employing SEM technique would thus contribute to theory testing and to explain the relationships among the model constructs.

\section{Conclusions and Future Recommendation}

The fundamental objective of this study is to present and conceptually examine the relationships of the theoretical model among the dimensions of ICC, perceived cultural distance, customer satisfaction, previous experience, inter-role congruence and interaction comfort. The theoretical model presented in the study postulates that previous experience predicts perceived cultural distance. Perceived cultural distance and ICC predicts interrole congruence and interaction comfort. Finally, inter-role congruence and interaction comfort influence customer satisfaction.

The possible findings are anticipated to produce meaningful improvement in managing and understanding the cross-cultural communication constructs in the practice and beyond the theory. The implications for further research would be to test both the indirect and direct effects of the model on customer satisfaction in various multicultural atmospheres. The main administrative implication from the study will be that assessments of communication experience in terms of the intercultural communication in addition to the conventional cognitive assessment of the normal perspectives. To scholars, the study would assist in strategizing ICC effectively when operating in multiracial atmosphere. The primary concern of Malaysian authorities is to decrease internal and external communication issues in multiracial atmospheres that is the most active and strategically significant situations. Promoting ICC will not just improve the competitiveness among the multiethnic encounters but would also boost the racial integration and the government campaign on unity program. Another positive outcome of the study would be the re-defining and re-conceptualizing the communication and raise the highly skilled employees with strong ICC aptitude among participants. 


\section{References}

Ahmad, F. S., Ihtiyar, A., \& Omar, R. (2015). A conceptual framework to explain the role of social environment and multicultural personality on intercultural communication competency, inter role congruence and interaction comfort. International Journal of Finance, Business, Economics, Marketing and Information Systems, 1(1), $1-14$.

Ahmad, F. S., Ihtiyar, A., \& Omar, R. (2014). A comparative study on service quality in the grocery retailing: Evidence from Malaysia and Turkey. Procedia-Social and Behavioral Sciences, 109, 763-767.

Ahmad, F. S., Ihtiyar, A., Jing, W., \& Osman, M. H. M. (2012, January). Integrating brand perception, cultures dimension and social influence in predicting purchase intention in luxury brand market. Paper presented at the Third International Conference on Business and Economic Research, Selangor, Indonesia.

Ali, F., Hussain, K., \& Ragavan, N. A. (2014). Memorable customer experience: Examining the effects of customers experience on memories and loyalty in Malaysian resort hotels. Procedia-Social and Behavioral Sciences, 144, 273-279.

Baker, T. L., Cronin Jr, J. J., \& Hopkins, C. D. (2009). The impact of involvement on key service relationships. Journal of Services Marketing, 23(2), 114-123.

Biddle, B. J. (1979). Role theory: Expectations, identities, and behaviors. New York, NY: Academic Press.

Cetin, G., \& Dincer, F. I. (2014). Influence of customer experience on loyalty and word-of-mouth in hospitality operations. Anatolia, 25(2), 181-194.

Chen, H. G., Liu, J. Y. C., Sheu, T. S., \& Yang, M. H. (2012). The impact of financial services quality and fairness on customer satisfaction. Managing Service Quality, 22(4), 399 - 421

Cho, K. R., \& Padmanabhan, P. (2005). Revisiting the role of cultural distance in MNC's foreign ownership mode choice: The moderating effect of experience attributes. International Business Review, 14(3), 307-324.

Cleveland, M., Laroche, M., \& Papadopoulos, N. (2009). Cosmopolitanism, consumer ethnocentrism, and materialism: An eight-country study of antecedents and outcomes. Journal of International Marketing, 17(1), 116-146.

Danylova, T. (2013). Awakening our awareness: Parables in intercultural dialogue. International Journal of Social Science \& Management 1(11), 1-3.

Earley, P. C., Murnieks, C. \& Mosakowski, E. (2007). Cultural intelligence and the global mindset. Advances in International Management, 19, 75-103.

Friedman, V. J., \& Antal, A. B. (2005). Negotiating reality: A Theory of action approach to intercultural competence. Management Learning, 36(1), 69-86.

Golder, P. N., Mitra, D., \& Moorman, C. (2012). What is quality? An integrative framework of processes and states. Journal of Marketing, 76 (4), 1-23.

Hair Jr, J. F., Hult, G. T. M., Ringle, C., \& Sarstedt, M. (2013). A primer on partial least squares structural equation modeling (PLS-SEM): London, UK: SAGE.

Han, H., Kim, Y., \& Kim, E. K. (2011). Cognitive, affective, conative, and action loyalty: Testing the impact of inertia. International Journal of Hospitality Management, 30(4), 1008-1019.

Herzog, C. (2010). Intercultural communication conflicts. Munich, Germany: GRIN Verlag.

Hill, S. R., \& Tombs, A (2011). The effect of accent of service employee on customer service evaluation. Managing Service Quality. 21(6), 649 - 666.

Hofstede, G. (1984). Culture's consequences: International differences in work-related values (Vol. 5). London, UK: Sage.

Hui, T. K., Wan, D., \& Ho, A. (2007). Tourists' satisfaction, recommendation and revisiting Singapore. Tourism Management, 28(4), 965-975.

Hunt, J. B., \& Wallace, J. (1997). A competence-based approach to assessing managerial performance in the Australian context. Asia Pacific Journal of Human Resources, 35(2), 52-66.

Ihtiyar, A., \& Fauziah, S. (2015a). The role of intercultural communication competence on service reliability and customer satisfaction. Journal of Economic and Social Studies, 5(1), 145-168.

Ihtiyar, A., \& Ahmad, F. S. (2015b). The impact of intercultural communication competence on service quality and customer satisfaction. Services Marketing Quarterly, 36(2), 136-152.

Ihtiyar, A., Ahmad, F. S., \& Baroto, M. B. (2013). Impact of intercultural competence on service reliability and customer satisfaction in the grocery retailing. Procedia - Social and Behavioral Sciences, 99(0), 373-381. http://dx.doi.org/10.1016/j.sbspro.2013.10.505

Ihtiyar, A., \& Ahmad, F. S. (2012). Measurement of perceived service quality in the food retail industry of Turkey. International Business Management, 6(2), 249-255. 
Li, H., Ye, Q., \& Law, R. (2013). Determinants of customer satisfaction in the hotel industry: An application of online review analysis. Asia Pacific Journal of Tourism Research, 18(7), 784-802.

Lloyd, A. E., \& Luk, S. T. (2011). Interaction behaviors leading to comfort in the service encounter. Journal of Services Marketing, 25(3), 176-189.

Lustig, M. W., \& Koester, J. (2009). Intercultural competence: Interpersonal communication across cultures. New York, NY: Pearson

Kim, A. K., \& Brown, G. (2012). Understanding the relationships between perceived travel experiences, overall satisfaction, and destination loyalty. Anatolia: An International Journal of Tourism and Hospitality Research, 23(3), 328-347.

Kim, J. Y., Kim, J. Y., \& Miner, A. S. (2009). Organizational learning from extreme performance experience: The impact of success and recovery experience. Organization Science, 20(6), 958-978.

Lewis, R. C., \& Chambers, R. E. (2000). Marketing leadership in hospitality. New York, NY: John Wiley and Sons.

McKercher, B., Wong, C., \& Lau, G. (2006). How tourists consume a destination. Journal of Business Research, 59(5), 647-652.

Messner, W., \& Schäfer, N. (2012) The ICCA facilitator's manual: Intercultural communication and collaboration appraisal. London, UK: GloBus Research.

Michel, S., \& Meuter, M. L. (2008). The service recovery paradox: True but overrated? International Journal of Service Industry Management, 19(4), 441-457.

Mokhlis, S. (2009). Malaysian Chinese consumers: Their ethnic attitudes and shopping orientations. International Journal of Business and Management, 4(11), 53-62.

Mossberg, L. (2007). A marketing approach to the tourist experience. Scandinavian Journal of Hospitality and Tourism, 7(1), 59-74.

Nam, J., Ekinci, Y., \& Whyatt, G. (2011). Brand equity, brand loyalty and consumer satisfaction. Annals of Tourism Research, 38(3), 1009-1030.

Nicholls, R. (2011). Customer-to-customer interaction (CCI): A cross-cultural perspective. International Journal of Contemporary Hospitality Management, 23(2), 209-223.

Oh, H., Fiore, A. M., \& Jeoung, M. (2007). Measuring experience economy concepts: Tourism applications. Journal of Travel Research, 46(2), 119-132.

Oliver, R. L., Rust, R. T., \& Varki, S. (1997). Customer delight: Foundations, findings, and managerial insight. Journal of Retailing, 73(3), 311-336.

Paswan, A. K., \& Ganesh, G. (2005). Cross-cultural interaction comfort and service evaluation. Journal of International Consumer Marketing, 18(1-2), 93-115.

Polsa, P., Fuxiang, W., Sääksjärvi, M., \& Shuyuan, P. (2013). Cultural values and health service quality in China. International Journal of Health Care Quality Assurance, 26(1), 55-73.

Raajpoot, N. (2004). Reconceptualizing service encounter quality in a non-western context. Journal of Service Research, 7(2), 181-201.

Ramanathan, R. (2012). An exploratory study of marketing, physical and people related performance criteria in hotels. International Journal of Contemporary Hospitality Management, 24(1), 44-61.

Reimann, M., Lünemann, U. F., \& Chase, R. B. (2008). Uncertainty avoidance as a moderator of the relationship between perceived service quality and customer satisfaction. Journal of Service Research, 11(1), 63-73.

Rusbult, C. E., \& Van Lange, P. A. (2003). Interdependence, interaction, and relationships. Annual Review of Psychology, 54(1), 351-375.

Rusbult, C. E., \& Van Lange, P. A. (2008). Why we need interdependence theory. Social and Personality Psychology Compass, 2(5), 2049-2070.

Ryoo, H. K. (2005). Achieving friendly interactions: a study of service encounters between Korean shopkeepers and African-American customers. Discourse \& Society, 16(1), 79-105.

Sánchez-Hernández, R. M., Martínez-Tur, V., Peiró, J. M., \& Ramos, J. (2009). Testing a hierarchical and integrated model of quality in the service sector: Functional, relational, and tangible dimensions. Total Quality Management, 20(11), 1173-1188.

Sharma, P., Tam, J. L., \& Kim, N. (2012). Intercultural service encounters (ICSE): An extended framework and empirical validation. Journal of Services Marketing, 26(7), 521-534.

Shekarchizadeh, A., Rasli, A., \& Hon-Tat, H. (2011). SERVQUAL in Malaysian universities: Perspectives of international students. Business Process Management Journal, 17(1), 67-81.

Sim, J., Mak, B., \& Jones, D. (2006). A model of customer satisfaction and retention for hotels. Journal of Quality Assurance in Hospitality \& Tourism, 7(3), 1-23. 
Sizoo, S., Iskat, W., Plank, R., \& Serrie, H. (2004). Cross-cultural service encounters in the hospitality industry and the effect of intercultural sensitivity on employee performance. International Journal of Hospitality \& Tourism Administration, 4(2), 61-77.

Sizoo, S., Plank, R., Iskat, W., \& Serrie, H. (2005). The effect of intercultural sensitivity on employee performance in cross-cultural service encounters. Journal of Services Marketing, 19(4), 245-255.

Solomon, M. R., Surprenant, C., Czepiel, J. A., \& Gutman, E. G. (1985). A role theory perspective on dyadic interactions: The service encounter. The Journal of Marketing, 49(1), 99-111.

Spake, D. F., Beatty, S. E., Brockman, B. K., \& Crutchfield, T. N. (2003). Consumer comfort in service relationships measurement and importance. Journal of Service Research, 5(4), 316-332.

Su, L., Swanson, S. R., \& Chen, X. (2016). The impact of perceived service fairness and quality on the behavioral intentions of Chinese hotel guests: The mediating role of consumption emotions. Journal of Travel \& Tourism Marketing, 33(1), 88-102.

Surprenant, C. F., Solomon, M. R., \& Gutman, E. G. (1983). Service encounters are human interactions. Journal of Business research, 20(1), 13-21.

Statistics Department of Malaysia. (2013). Population projection report. Retrieved from http://www.statistics.gov.my/portal/images/stories/files/LatestReleases/population/Ringkasan_PenemuanSummary_Findings_2010-2040.pdf

Thomas, D. C., Elron, E., Stahl, G., Ekelund, B. Z., Ravlin, E. C., Cerdin, J. L., Aycan, Z. (2008). Cultural intelligence domain and assessment. International Journal of Cross Cultural Management, 8(2), 123-143.

Tourism Malaysia. (2015). Tourist arrivals. Retrieved from http://corporate.tourism.gov.my/research.asp?page=facts_figures

Wang, Z., Arndt, A., Singh, S., \& Biernat, M. (2009). The impact of accent stereotypes on service outcomes and its boundary conditions. Advances in Consumer Research, 36, 940-941.

Weaver, G. R. (1998). Culture, communication and conflict: Readings in intercultural relations. New York, NY: Pearson

Wu, C. H. J., \& Liang, R. D. (2009). Effect of experiential value on customer satisfaction with service encounters in luxury-hotel restaurants. International Journal of Hospitality Management, 28(4), 586-593

Yang, C. C., Jou, Y. T., \& Cheng, L. Y. (2011). Using integrated quality assessment for hotel service quality. Quality \& Quantity, 45(2), 349-364.

Yim, C. K., Tse, D. K., \& Chan, K. W. (2008). Strengthening customer loyalty through intimacy and passion: Roles of customer-firm affection and customer-staff relationships in services. Journal of Marketing Research, 45(6), 741-756.

Yuksel, A., Kilinc, U., \& Yuksel, F. (2006). Cross-national analysis of hotel customers' attitudes toward complaining and their complaining behaviors. Tourism Management, 27(1), 11-24.

Zemke, D. M. V., \& Pullman, M. (2008). Assessing the value of good design in hotels. Building Research \& Information, 36(6), 543-556.

Zhang, X. J., \& Li, H. M. (2009). Budget hotel customer satisfaction analysis based on SERVQUAL model. Strategic Management Engineering: Enterprise, Environment and Crisis, 1, 64-68. 